\title{
ANALYSIS OF OILSEED RAPE STEM WEEVILS CHEMICAL CONTROL USING DAMAGE RATING SCALE
}

\author{
Authors \\ Željko Milovac ${ }^{\mathrm{a}^{*}}$, Miroslav Zorića ${ }^{\mathrm{a}}$ Filip Franeta ${ }^{\mathrm{a}}$, Sreten Terzića ${ }^{\mathrm{a}}$, Olivera Petrović \\ Obradović $^{b}$, Ana Marjanović Jeromela ${ }^{\mathrm{a}}$ \\ *Correspondence to: Željko Milovac, Rapeseed division, Oil crops department, Institute of \\ Field and Vegetable Crops, Maksima Gorkog 30, 21000 Novi Sad, Serbia. \\ E-mail: zeljko.milovac@nsseme.com; mob.+381648706075; fax +381216413833 \\ ${ }^{\mathrm{a}}$ Institute of Field and Vegetable Crops, Maksima Gorkog 30, 21000 Novi Sad, Serbia \\ ${ }^{b}$ Faculty of Agriculture, University of Belgrade, Nemanjina 6, 11080 Belgrade, Serbia
}

\begin{abstract}
BACKGROUND: Rape stem weevil (Ceutorhynchus napi Gyll.) and cabbage stem weevil (C. pallidactylus Marsh.) can cause significant yield losses to oilseed rape (Brassica napus L.), and chemical control is often needed to protect crops from these pests. The efficacy of six insecticides, chlorpyriphos+cypermethrin, bifenthrin, alpha-cypermethrin, pirimiphos-methyl, thiacloprid and tau-fluvalinate, was tested in a four year field trial. Besides the standard
\end{abstract}

This article has been accepted for publication and undergone full peer review but has not been through the copyediting, typesetting, pagination and proofreading process, which may lead to differences between this version and the Version of Record. Please cite this article as doi: 10.1002/ps.4568

This article is protected by copyright. All rights reserved. 
efficacy analysis expressed through the number of larvae per stem, a damage rating scale was introduced and modelled using a regression model for ordinal categorical data.

RESULTS: Compared with the control, expressed through damage rating and larval number, treatments with chlorpyriphos+cypermethrin and bifenthrin, showed higher efficacy in the control of stem weevils compared to alpha-cypermethrin and pirimiphos-methyl. The lowest efficacy was observed in treatments with tau-fluvalinate and thiacloprid.

CONCLUSION: This study showed that a combined efficacy evaluation expressed through both damage rating scale and the count of larvae, supported by an ordinal regression model for data analysis, is indispensable for obtaining accurate results.

Keywords: Ceutorhynchus napi; Ceutorhynchus pallidactylus; chemical control; insecticide efficacy; proportional odds model

\section{INTRODUCTION}

The constant population expansion and its food requirements as well as a pronounced diversification of uses of Brassica products, more demand for biofuels i.e. biodiesel, influenced a steady increase in oilseed rape (Brassica napus L.) production worldwide in the last decades (FAOSTAT 2013). In conjunction with the growing acreage under this crop, the average yield has also increased. These facts, coupled with plant-breeding approaches, seed quality improvement and modification of fatty acid profiles, made a significant contribution to the increasing popularity of this crop. ${ }^{1}$ With the acreage increase the protection of oilseed rape became more complex due to a higher pests pressure. Insects are a significant yield decreasing factor in oilseed rape production with $13 \%$ yield loss on average on global and

This article is protected by copyright. All rights reserved. 
$15 \%$ on European level. ${ }^{2}$ In some cases yield losses can reach $24.5 \%{ }^{3}$ or even more than $80 \%{ }^{4}$ A wide range of insect species are considered as oilseed rape pests, especially from the Coleoptera, Lepidoptera, Hymenoptera and Diptera orders. ${ }^{4}$ The rape stem weevil (Ceutorhynchus napi Gyll.) and cabbage stem weevil (C. pallidactylus Marsh.) are among six of the most dangerous oilseed rape pests in Europe. ${ }^{5,6}$

The rape stem weevil and cabbage stem weevil, later in the text referred to as stem weevils, damage the plant stem in which their larvae feed. As a consequence, the damaged plants produce less pods. They also induce plant lodging, making harvest more demanding and increase pod shattering. ${ }^{7}$ Damaged plants are also more susceptible to the pathogenic fungus Leptosphaeria maculans (Desm.) Ces. et De Not. (anamorph Phoma lingam (Tode) Desm. $^{5}$

The oilseed rape yield decrease caused by stem weevils is dependent on many factors, among which prevail the pest's abundance, climatic conditions and plants compensation abilities. ${ }^{8}$ Stem weevils can cause significant yield losses, ${ }^{5}$ and some authors indicate they can vary from $5 \%{ }^{9}$ up to $32 \%$ or more ${ }^{8}$ or to account for a loss of up to $800 \mathrm{~kg} / \mathrm{ha}{ }^{7}$ Even cases with larval presence on $100 \%$ of plants are recorded. ${ }^{7,10}$

Widespread resistance in pest populations and increasing public concern about environmental hazards of pesticides are threatening the availability of a variety of insecticides. ${ }^{11}$ There is a need to avoid any overuse or misuse of insecticides in order to minimize the risk of resistance development. Several insect species need to be controlled within a short period of a few weeks, which results in a higher selection pressure. ${ }^{11}$ Pyrethroid resistance of the pollen beetle (Meligethes aeneus F.) is steadily spreading and increasing from 2005 onwards. Lack of sensitivity in Psylliodes chrysocephala (L.) and Ceutorhynchus obstrictus (Marsham) was also detected. ${ }^{12}$ Due to these facts, the chemical control of stem weevils should be done with precautions in order to avoid possible resistance.

This article is protected by copyright. All rights reserved. 
In situations when the economical threshold is reached, stem weevils are controlled with insecticides. Even though pyrethroids are currently dominating the insecticide market for weevils control, ${ }^{11}$ they show relatively low persistence in the field and lack of systemic activity. Similarly to organophosphorus compounds, they also have broad-spectrum effects on target and non-target insects. Neonicotinoids are insecticides with contact and systemic activity with a different mode of action than the previous groups. ${ }^{13}$ Those insecticides also belong to different groups according to Insecticide Resistance Action Committee (IRAC) due to resistance management (Table 1). Furthermore, tau-fluvalinate is not hazardous for honeybees at recommended doses, ${ }^{13}$ which is why its efficacy and possible use for stem weevils control were evaluated.

The main objectives of this study were to: a) devise a specific method for damage assessment based on ordinal ratings scale, instead of the more commonly used "larvae per stem" efficacy assessment, b) apply an ordinal categorical regression model for data analysis and test its prediction accuracy across the four trial years, c) assess the efficacy of insecticides belonging to different chemical groups (pyrethroids, organophosphates and neonicotinoids), in field conditions for controlling stem weevils in oilseed rape,

The obtained results will be used to optimise chemical control so that it meets high efficacy demands with the lowest number of applications. In that way, the environment and the non-target insect populations, such as pollinators and beneficial insects, will be more preserved, while the possibility of resistance occurrence should also be reduced.

\section{MATERIAL AND METHODS}

\subsection{Experimental site}

This article is protected by copyright. All rights reserved. 
Experiments were carried out in the trial fields of the Institute of Field and Vegetable Crops at

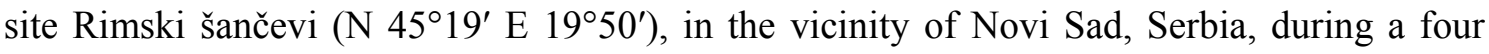
year period under natural pest infestation. Trials were set up using a randomized block design in four replications according to European and Mediterranean Plant Protection Organization (EPPO) standards. ${ }^{14}$ The size of the experimental basic plot was $25 \mathrm{~m}^{2}, 6 \mathrm{~m}$ long and $4.2 \mathrm{~m}$ wide. For this trial, winter oilseed rape variety Banaćanka was used, listed as a control variety on the Serbian national list of registered varieties. Growing technology was conformed to local agricultural practice. Row-to-row distance was $25 \mathrm{~cm}$ with $5 \mathrm{~cm}$ spacing between plants in rows.

\subsection{Insecticides properties}

The used insecticides were chosen according to mode of action, impact on nonharmful animals and belong to three different chemical groups: pyrethroids, organophosphates and neonicotinoids. Insecticides used in the trials, their commercial names, amount of active ingredient (a.i.), application rate and IRAC resistance groups are given in Table 1.

\subsection{Insecticide application}

Insecticide application was done using "Solo accu power 416" sprayer with XR Teejet $11003 \mathrm{VK}$ nozzles and constant pressure of 2 bar $(200 \mathrm{KPa})$ with 350 liters of water per hectare on $30^{\text {th }}$ of March in 2010, on $4^{\text {th }}$ of April in 2011, on $3^{\text {th }}$ of April in 2012 and on $12^{\text {th }}$ of April in 2013. The partly delayed spraying in 2013 was due to unfavourable weather conditions during the end of March and at the beginning of April. At the time of foliar treatments, oilseed rape was in the second half of intensive stem elongation, designated as

This article is protected by copyright. All rights reserved. 
phenological growth stages BBCH 36-39; BBCH 36 in 2010, BBCH 37 in 2011. and 2012. and $\mathrm{BBCH} 39$ in $2013 .^{21}$

\subsection{Insect damage assessments}

According to EPPO standards, ${ }^{14}$ the number of larvae occurring in stems should be counted with assessment of damage symptoms. The dissections were done at BBCH 67 growth stage $\mathrm{e}^{21}$ except in 2012 when it was done at growth stage 69 due to unfavourable weather conditions. In order to evaluate the actual damage caused by larvae, an assessment using six points damage rating scale was performed (Table 2). For this purpose we used a modified scale described by Seidenglanz. ${ }^{22}$ Plants without damage and no recorded weevils were rated as zero. Slightly damaged plants with tunnels in stems up to $10 \%$ of stem length were rated one, plants with longer tunnels (11 to $25 \%$ of stem) and with low lodging probability were rated two. Plants with 26 to $50 \%$ of damaged stem were rated three while rating four was assigned to plants with tunnels ranging from 51 to $75 \%$ of stem length and high lodging probability. Plants with rating five had most of stem damaged (more than $76 \%$ ) and almost certain lodging probability. Plant damage assessed with rating three or higher can be considered as economically significant.

Twenty plants per plot i.e. eighty per treatment were dissected and thoroughly analysed. In each plant the number of larvae per stem and exit holes were counted. Additionally, every dissected stem was marked according to the damage rating scale (Table 2). It is worth mentioning that last instar larvae leave the stems through exit holes in order to find a suitable pupation location. ${ }^{5,6}$ Taking this fact into consideration, the time of assessment plays a significant role in insecticides efficacy evaluation in case of oilseed rape stem weevils' control. That is why, the introduction of damage scale (with an appropriate statistical model) should be considered as more accurate and less dependent on the time of evaluation.

This article is protected by copyright. All rights reserved. 


\subsection{Stem weevils monitoring}

Yellow water traps (Moericke dishes) were used to monitor the weevil's flight and thus obtain information about insect abundance (Table 3 ) and the optimal time for insecticide treatment. Four yellow traps were randomly placed across the experimental field. Cabbage stem weevil and rape stem weevil in this area usually occur at the same time $e^{15,16}$ and chemical control, if needed, can be done simultaneously for both species with a single foliar spraying. The sampled weevils of both species and their sexes were identified according to several identification keys. ${ }^{17,18,19,20}$ During this period the ratio between the two weevil species was established to be almost 1:1 $(0,93)$ and the sex ratio for the rape stem weevil was 0.49 and the cabbage stem weevil was 0.37 as shown in table 4 . The economic threshold for the two weevil species varies among different regions and it is based on their abundance and damage capabilities. For the cabbage stem weevil a threshold of 10-20 specimens per yellow water trap within three consecutive days is usually acceptable for Central Europe, while for the rape stem weevil a threshold of 10 specimens per yellow water trap within three consecutive days is used ${ }^{5}$. Other authors mention different thresholds of 4-6 rape stem weevil specimens and 12 cabbage stem weevil specimens for the same monitoring conditions. ${ }^{9}$ Due to practical difficulties for agricultural producers to separate the two species, thresholds in some regions are given as one value of 10 specimens per yellow water trap within three consecutive days. ${ }^{5}$

\subsection{Statistical analysis}

Data on insect damage collected during the course of the experiment consists of categorical scales that have a natural ordering of values (i.e., damage rating $0<$ damage rating $1<\ldots<$ damage rating $I$ ). If the variable $(Y)$ has natural order, a variety of the regression models are capable to incorporate this ordering exploiting various logit transformations of the

This article is protected by copyright. All rights reserved. 
response probabilities. If we suppose that $Y$ has underlying logistic distribution and that the damage ratings have spacing on continuous scale, the damage rating 0 will represent the plants as $Y<\theta_{0}$, where $\theta$ represents the first cut-point. The probability $\left(\pi_{0}\right)$ of the scoring of the plant with damage rating 0 is $P\left(Y<\theta_{0}\right)$. The damage rating 2 represent the plants between $\theta_{0}$ and $\theta_{1}$ and the probability $\left(\pi_{1}\right)$ of the scoring of the plants with this rating is defined as $P\left(\theta_{1}\right.$ $<Y<\theta_{2}$ ). By applying the ordinal categorical regression model, we estimate the cut-points and probabilities. On a six-point damage rating scale five cut-points need to be estimated $\left(\theta_{0}\right.$, $\left.\ldots, \theta_{4}\right)$ and five probabilities $\left(\pi_{0}, \ldots, \pi_{4}\right)$. These can be expressed by estimating cumulative probabilities $\left(\gamma_{0}, \ldots, \gamma_{5}\right)$ as $\gamma_{0}=P\left(Y<\theta_{0}\right)=\pi_{0}, \gamma_{1}=P\left(Y<\theta_{1}\right)=\pi_{0}+\pi_{1}, \ldots, \gamma_{5}=P\left(Y<\theta_{5}\right)=\pi_{0}+$ $\pi_{1}+\pi_{2}+\pi_{3}+\pi_{4}+\pi_{5}$. The modeling of the cumulative probabilities is based on the following ordinal logistic model: $\gamma_{i}=\frac{1}{1+e^{-\left(\theta_{i}-\beta_{1} X_{1}-\ldots\right)}}$; where $\theta_{i}$ are the cut-points and $X_{1}$ is the independent variable i.e. insecticide treatment. On the logit scale the model can be expressed as $\log \left(\frac{\gamma_{i}}{1-\gamma_{i}}\right)=\theta_{i}-\beta_{1} X_{1} \ldots$ for damage ratings $i=1,2, \ldots$. The most important feature of this model is that the logit of the cumulative probabilities changes linearly as the independent variable changes and that the slope is the same regardless on the damage rating category $i$. Due to this feature the model is referred as the proportional odds model or more precisely proportional odds version of the cumulative logit model. ${ }^{23,24}$ For the purpose of this research, insecticide treatments are evaluated in the terms of the estimated and cumulative probabilities. For estimating the unknown parameters of the model, the maximum likelihood method was used. The statistical inference about the parameters of the model was performed by applying Wald's test which under the null hypothesis has an approximate chi-square distribution. ${ }^{25}$

The predictive accuracy of the model was measured by calculating the nonparametric correlation coefficients between the cumulative probabilities and the number of plants within 
each insecticide treatment which are classified into respective damage categories during the field assessment procedure.

The multidimensional scaling (MDS) technique is a multivariate data reduction technique. ${ }^{26}$ Similar to classic principal component analysis, MDS technique allows for the visualization of distance matrices. MDS projects the data onto a lower dimensional space using a proximity measure, i.e. a distance or a similarity measure between the samples of the matrix. The main objective for using MDS technique is to find a lower-dimensional representation of the distance matrix, while preserving the pairwise distances as good as possible. In order to visualize the relationships between the cumulative probabilities from the yearly individual models, Euclidean geometric distance was estimated and visualized in the two-dimensional MDS plot.

All data analyses and data visualizations were accomplished within the $\mathrm{R}$ environment. $^{27}$

\section{RESULTS}

During the trial period, from 2010 to 2013 , a great variation in intensity of stem weevil abundance was observed. If the infestation severity is analysed using the number of plants without larval presence it can be noticed that 2010 was the year with the highest damage ( $4.1 \%$ of plants without symptoms), while 2011 was with the lowest pest incidence $(38.9 \%)$. In 2012 , that number was $8.8 \%$ and $11 \%$ in 2013 (data not shown). The highest number of larvae recorded in one plant was 62 (in 2010) and the number of exit holes 24 (data not shown).

\subsection{Insecticide efficacy expressed through number of larvae in stem}

This article is protected by copyright. All rights reserved. 
In the first year of the experiment, the highest average number of larvae in stem was recorded in the control treatment, with a value of 11.8 (Table 5). Similar results were obtained in treatments with tau-fluvalinate and thiacloprid (11.5 and 10.5 respectively). Alphacypermethrin, chlorpyriphos+cypermethrin and pirimiphos-methyl had lower larval numbers, ranging from 5.0 to 5.8. Bifenthrin had the value 3.3 with the highest efficacy. The second year, as previously mentioned, had the lowest pest incidence, far less than the economical threshold, and that is why differences between treatments were not more expressed. Treatments with the highest larval numbers in stem were thiacloprid and tau-fluvalinate, 1.9 and 1.4 respectively (Table 5). The control treatment had value 1.0 and bifenthrin 1.3 , while other treatments ranged from 0.7 to 1.1 . In the third year, the highest larval number was recorded in the control treatment, 3.7 (Table 5). This was followed by thiacloprid which had a value of 3.1, while tau-fluvalinate and alpha-cypermethrin treatments had values 2.6 and 2.4, respectively. The lowest values were recorded in treatments with pirimiphos-methyl, bifenthrin and chlorpyriphos+cypermethrin, 1.9, 1.8 and 1.5 respectively. The last trial year 2013, showed that the control treatment had the highest larval number 2.8, followed by thiacloprid and tau-fluvalinate treatments, 2.3. Pirimiphos-methyl succeeded with 2.2, while alpha-cypermethrin and chlorpyriphos+cypermethrin had values of 1.4 and 1.6. The lowest value was recorded in the bifenthrin treatment, 0.9 .

\subsection{Insecticide efficacy expressed through damage ratings}

Insecticide efficacy was tested using damage ratings and appropriate regression model, proportional odds model, for ordered categorical data. In the first year of the trial all tested insecticides except tau-fluvalinate and thiacloprid were significantly different compared to the control. In the second year alpha-cypermethrin and pirimiphos-methyl showed highly significant differences $(\mathrm{P}<0.01)$, while chlorpyriphos+cypermethrin was significantly 
different $(\mathrm{P}<0.05)$. In the third year, only thiacloprid was not significantly different. In the last year all treatments showed highly significant differences $(\mathrm{P}<0.01)$ concerning insect damage, when compared with control treatment (Table 6).

\subsection{Treatments classification based on the proportional odds model}

In order to analyse the obtained data using damage ratings, a comparison of the estimated and cumulative probabilities between the treatments is presented in Table 7 . The estimated probabilities show that a certain treatment will not receive a category higher than that given by damage rating scale. Probabilities for categories four and five are discussed in more details as they indicate the highest pest intensity and the highest yield loss probability. In 2010 , the first trial year, the estimated probability for rating four was the lowest for control (0.354), and the highest for bifenthrin (0.806). The estimated probability for rating five was similar with the previous one, lowest for the control (0.743) and highest for bifenthrin (0.956). Other treatments had values above 0.9 except tau-fluvalinate $(0.799)$ and thiacloprid $(0.81)$ (Table 7). In the following year the estimated probabilities increased from rating three, which confirms that this year had low pest incidence. The lowest values are for control (0.704) and thiacloprid (0.709) treatments. Values for tau-fluvalinate $(0.781)$ and bifenthrin $(0.794)$ were lower than 0.8 , while all other treatments had higher values. Ratings four and five exceed 0.9 for all treatments and will not be subject of detailed analysis. The estimated probabilities for rating four were the lowest for control (0.114) and thiacloprid (0.195) in 2012. The highest value was recorded in chlorpyriphos+cypermethrin combination (0.586). Estimated probabilities for rating five varied from the lowest in control $(0.236)$ to the highest in bifenthrin (0.703) and chlorpyriphos+cypermethrin (0.772) treatments. Table 7 also presents estimated probabilities for 2013, the last experimental year, where values for rating three are the lowest for control (0.380) and the highest for bifenthrin (0.874) and 
chlorpyriphos+cypermethrin (0.918). Estimated probabilities for rating four are higher than 0.849 with the exception of control treatment (0.722).

Table 8 gives information based on cumulative probabilities, i.e. average probability for a treatment to be classified in a given category. In the first trial year 2010, the highest cumulative probability was for rating four, and varied from 0.389 to 0.363 for control, taufluvalinate and thiacloprid treatments (Table 8). For the other four treatments the variation ranged from 0.293 to 0.329 for rating three. In the second trial the highest cumulative probabilities were obtained for rating zero and they varied from 0.277 for control to 0.56 for pirimiphos-methyl (Table 8). Cumulative probabilities for rating one was between 0.185 and 0.205 for all treatments and varied from 0.182 to 0.236 for rating two, with the exception of pirimiphos-methyl $(0.142)$. In the third year, the cumulative probability for rating five was the highest for control treatment $(0.764)$, while for the other treatments it varied from 0.228 to 0.633. Values for other ratings are lower. Data obtained in 2013 suggest that control treatment had the highest probability of taking rating three $(0.342)$, while treatments with alphacypermethrin, pirimiphos-methyl, tau-fluvalinate and thiacloprid had the highest probability for rating two (0.341 to 0.359$)$. Treatments with bifenthrin and chlorpyriphos+cypermethrin showed the highest probability for rating one ( 0.404 and 0.422 respectively).

\subsection{Treatments grouping using MDS technique}

The MDS technique was employed with the aim of low dimensional representation of the treatment behaviour during the experiment. Figure 1 presents the two-dimensional solution of the MDS technique where the first dimension accounts for $63.4 \%$ and the second for additional $25.6 \%$ of the original distance matrix which is derived from cumulative probabilities (Table 8). The first dimension clearly separates treatments from years 2011 and 2012 into two non-overlapping clusters. Treatments from 2013 are intermediate between two

This article is protected by copyright. All rights reserved. 
previously mentioned clusters. Furthermore, the second dimension separates treatments from 2011 and 2012 from 2010 and 2013 with several outliers in years 2011 and 2013. Treatments in 2013: bifenthrin and chlorpyriphos+cypermethrin showed similarities with the treatments in 2011. Distinct grouping pattern between the treatments among the years highlights the predominant effect of year on insect behaviour and consequently different ranking of treatments in terms of cumulative probabilities (Tables 7 and 8).

\section{DISCUSSION}

\subsection{Weather conditions}

Abundance of stem weevils in oilseed rape crops and the damage they cause depend on several factors. Weather conditions, especially temperature, strongly influence the pests activity and behaviour and their interaction with plants. ${ }^{28}$ Cabbage stem weevils resume their activity when soil temperature exceeds $6^{\circ} \mathrm{C},{ }^{29}$ and the flight starts at $12^{\circ} \mathrm{C}$, while rape stem weevils flight starts at $9-10^{\circ} \mathrm{C} .^{7}$ Temperature fluctuations decreased and partly postponed stem weevils' activity in 2013, when in the last decade of March a rapid temperature drop was followed by snow. Such variations are not unusual. In trials in the Czech Republic from 2006 to 2008 , the mean number of larvae per stem in control treatment varied from 0.55 to $9.23,{ }^{22}$ while in eastern Austria it ranged from 2 to 118 larvae per $\mathrm{m}^{2}$ depending on locality. ${ }^{30}$

Temperature is one of several critical factors affecting insect survival during winter diapause. ${ }^{41}$ Each insect species has a different response to environmental conditions. In a recent trial it has been proven that the winter survival of the cabbage stem weevil is greatly affected by higher temperatures during winter diapause. ${ }^{40}$ Higher than average temperatures negatively affect the survival of overwintering species by activating the specimens

This article is protected by copyright. All rights reserved. 
prematurely which accelerate the depletion of stored nutrients and lead to starvation. ${ }^{42}$ Eickermann et al. ${ }^{40}$ established that there are 2 distinct periods which affect the survival of $C$. pallydactilus. The first period is from day 14-18 (days from the beginning of the year) that regulates the end of diapause and the second from day 36 to 44 that control quiescence. Namely, if the average temperature in these critical periods is closer to $4.9^{\circ} \mathrm{C}$ than $1.2^{\circ} \mathrm{C}$ for the first period and $4.0^{\circ} \mathrm{C}$ than $-2.4^{\circ} \mathrm{C}$ for the second, no breaching of the threshold of 10 specimens per yellow water trap within three consecutive days is expected. Since the beginning of the flight season in our region coincides with the one in the mentioned study we attempted to validate these findings in our conditions. Table 9 shows the mean temperatures during the two critical periods. It can be seen that in the year with the lowest stem weevil abundance (2011) the mean temperature was $5.14^{\circ} \mathrm{C}$ in the first critical period and $2.67^{\circ} \mathrm{C}$ in the second, which is in accordance with the findings of Eickermann et al. ${ }^{40}$ Similar mean temperatures for the mentioned period $\left(4.02^{\circ} \mathrm{C}\right.$ and $\left.2.46^{\circ} \mathrm{C}\right)$ were recorded for 2013 which was also a year with lower pest abundance, however, the threshold of 10 specimens per yellow water trap within three days was breached. In 2010 the mean temperatures for the mentioned periods were $-0.22 \mathrm{C}$ and -1.06 which had positive effects on the insect survival while in 2012 due to frost problems and yellow water trap malfunctions the obtained results were not reliable.

Even though the threshold in 2011 was not breached, the insecticide application was still performed in order to test the model in a year with lower insect number. In such years the effect of insecticide is very low and it does not affect significantly the number of larvae, resulting in some treatments having similar values to the control.

\subsection{Assessment method and statistical analysis}

This article is protected by copyright. All rights reserved. 
Damage made by stem weevils is often underestimated due to indirect effects they have on plants. Because of complex influence these insects have on oilseed rape it is often hard to do appropriate assessments of insecticide efficacy. Usually it is done by counting larvae in plant stems, ${ }^{9,14,22,31,32,33}$ number of imagoes on plants, ${ }^{33}$ by dissecting plants and measuring tunnels ${ }^{10,34}$ and assessing damage. ${ }^{22,35}$ It is also possible to do assessments by counting the number of exit holes on stems. ${ }^{36}$ In cases of late assessments, the number of exit holes can be higher than the number of remaining larvae found in stems due to the fact that the larvae leave the stems prior to pupation. Furthermore, in case of untimely assessments, the number of larvae might be lower because egg laying can last for several weeks ${ }^{7,37}$ and the obtained results are likely to be inaccurate. For that reasons, damage assessments based on damage rating scales are essential for a reliable evaluation.

Damage ratings scale data analysis was performed using the proportional odds model, ${ }^{39}$ one of the most popular and widely used methods, although other alternatives are available when some of the model assumptions are not met. ${ }^{24,39}$ To support the proportional odds model as the efficient model in our study we evaluated the classification accuracy of one year model. The nonparametric correlation coefficients between the treatment cumulative probabilities and the number of plants within each treatment ranged mostly from 0.8 to 1.0 (data not shown) indicating that the models accurately classify the treatment into respective damage rating categories based on field assessments.

Data obtained through damage ratings and comparison of the treatments in terms of the estimated and cumulative probabilities and multidimensional scaling (MDS) coincide with larval number values and give a better insight in treatments efficacy. That is how, with slight differences in some years, three groups of insecticides, besides the control treatment, were distinguished. Highest efficacy was found for bifenthrin and the combination of 
chlorpyriphos + cypermethrin. Those two treatments expressed the highest ranking throughout all the years.

\subsection{Insecticide efficacy}

In our study, values for the larval number in stems, were the lowest for bifenthrin and chlorpyriphos+cypermethrin treatments, which represents the highest efficacy. Research conducted in Latvia showed that a combination of pyrethroids and neonicotinoids yielded better results than pyrethroids alone. ${ }^{38}$ Considering the percentage of infested plants and the number of larvae per plant, formulations based on chlorpyrifos+bifenthrin had certain advantages over formulations with deltamethrin, regardless of the application rate and number of treatments. ${ }^{33}$

Thiacloprid and tau-fluvalinate had the lowest efficacy in our trials, which is in contrast with the results of other researchers. This result for thiacloprid can be partly explained by the SC formulation which was used instead of OD like in some other experiments $^{36,38}$.

Alpha-cypermetrin and pirimiphos-methyl showed lower efficacy, but still achieved satisfying results. In trials conducted in Lithuania during 2005 and 2006 it has been shown that deltamethrin+thiacloprid, deltamethrin and alpha-cypermethrin had a highly significant influence on decreasing the number of exit holes ${ }^{36}$. In the same study the effects of betacyfluthrin+chlorpyrifos, beta-cyfluthrin and deltamethrin+thiacloprid were highly significant compared to the control concerning the number of damaged plants and exit holes in 2007 and 2008. It should be taken into account that all presented years were with lower pest pressure where the percentage of damaged stems in control treatments varied from 18.3 to 32.5 and the

number of exit holes from 0.11 to 0.33 . Seidenglanz et al. ${ }^{22}$ compared the effects of pyrethroid (alpha-cypermethrin) and a combination of organophosphates and pyrethroids

This article is protected by copyright. All rights reserved. 
(chlorpyrifos + cypermethrin) against $C$. pallidactylus in the Czech Republic in the period from 2006 to 2008. Both insecticides showed a significant reduction of the number of larvae in stems.

\section{CONCLUSION}

Due to the complex and often underestimated damage stem weevils can cause to oilseed rape, a detailed assessment of their harmful impact is indispensable. Results showed that the most applicable raw data are obtained through combined assessments of larval number and damage rating scale.

In order to properly account for the ordered nature of damage rating scales, a statistical model based on ordinal regression should be routinely recommended. As the ordinal variables follow the multinomial theoretical distribution, the use of traditional techniques based on ordinal least squares linear models like ANOVA is statistically questionable, since it is based on Gaussian distribution and different statistical assumptions. The proportional odds model showed a high degree of accuracy in the treatments classification when the model was referenced to the control treatment. Moreover, some other multivariate and visualization techniques like MDS can be applied on the estimated probabilities from the ordinal regression model to give further insight into data interpretation and conclusions.

Since the optimal period for chemical control of stem weevils is very short, there is usually time only for one foliar spraying, so it is important to select the insecticide with the highest efficacy. Among six tested insecticides from different chemical groups, treatments with chlorpyriphos+cypermethrin and bifenthrin expressed the highest efficacy and should be preferred to other insecticides in areas where pyrethroid resistance do not occur. These two

This article is protected by copyright. All rights reserved. 
treatments showed constant high efficacy throughout all years of the trial despite differences of pest pressure.

\section{ACKNOWLEDGEMENTS}

This research is a part of the project TR 31025 financed by the Ministry of Education, Science and Technological Development of the Republic of Serbia.

\section{REFERENCES}

1 Gupta SK, Advances in botanical research. Incorporating advances in plant pathology. Vol. 45. Rapeseed breeding. Elsevier. pp 554 (2007).

2 Cramer HH, Plant protection and world crop production. Pflanzenschutz-Nachrichten 'Bayer', 20, pp 1-524 (1967)

3 Kular JS and Kumar S, Quantification of avoidable yield losses in oilseed Brassica caused by insect-pests. J. Plant Prot. Res. 51, 1: 38-43 (2011).

4 Ahuja I, Rohlo J and Bones AM, Defence mechanisms of Brassicaceae: implications for plant-insect interactions and potential for integrated pest management. A review. Agronomy for Sustainable Development, Springer Verlag (Germany), 30 (2) (2010).

5 Alford VA, Nilsson C and Ulber B, Insect pests of oilseed rape crops. In: Biocontrol of oilseed rape pests ed. by Alford VA. Blackwell Science, Oxford, pp 9-41 (2003).

6 Williams HI, The Major Insect Pests of Oilseed Rape in Europe and Their Management: An Overview, in Biocontrol-based integrated management of oilseed rape pests, ed. by Williams HI. Springer, pp 1-44 (2010).

7 Juran I, Čuljak Gotlin T and Grubišić D, Rape Stem Weevil (Ceutorhynchus napi Gyll. 1837) and Cabbage Stem Weevil (Ceutorhynchus pallidactylus Marsh. 1802)

This article is protected by copyright. All rights reserved. 
(Coleoptera: Curculionidae) - Important Oilseed Rape Pests. Agriculturae Conspectus Scientificus. 76, 2: 93-100 (2011).

8 Kelm M and Klukowski Z, Weather as a factor determining damage caused by oilseed rape pests. Integrated Control in Oilseed Crops IOBC/WPRS Bulletin. 23, 6: $119-124$ (2000).

9 Spitzer T, Matušinsky P, Spitzerova D, Bilovsky J and Kazda J, Effect of flight activity of stem weevils (Ceutorhynchus napi, C. pallidactylus) and application time on insecticide efficacy and yield of winter oilseed rape. Plant Protect. Sci. 50, 3: 129 134 (2014).

10 Graham CW and Gould HJ, Cabbage stem weevil (Ceutorhynchus quadridens) on spring oilseed rape in Southern England and its control. Ann. appl. Biol. 95: 1-10 (1980).

11 Thieme T, Heimbach U and Müller A, Chemical control of insect pests and insecticide resistance in oilseed rape, in Biocontrol-based Integrated Management of Oilseed Rape Pests, ed. by Williams HI. Springer, pp 313-337 (2010).

12 Heimbach $U$ and Müller A, Incidence of pyrethroid-resistant oilseed rape pests in Germany. Pest Manag Sci 69: 209-216 (2013).

13 Tomlin S (ed), A world compendium. The pesticide manual. Fourteenth edition. British crop production council (2006).

14 Anonymous, EPPO standards. Efficacy evaluation of plant protection products. Volume 3. OEPP/EPPO, Paris. PP1/219(1), pp 245-247 (2004).

15 Milovac, Ž., Pešić, S., Kereši, T., Marinković, R, Weevils (Coleoptera: Curculionoidea) important members of rapeseed entomofauna in vicinity of Novi Sad. Kragujevac Journal of Science 32: 141-148 (2010).

This article is protected by copyright. All rights reserved. 
16 Sivčev I, Sivčev L, Pešić S, Graora D, Tomić V and Dudić B, Weevils of the genus Ceutorhynchus Germ associated with oilseed rape in northern Serbia. Pestic. Phytomed. (Belgrade), 30, 3: 155-159 (2015).

17 Alonso-Zarazaga MA and Lyal $\mathrm{CH}$, A world catalogue of families and genera of Curculionoidea (Insecta: Coleoptera) (Excepting Scolytidae and Platypodidae). Entomopraxis; Barcelona. (1999).

18 Angelov P, Fauna in Bulgaria, T-9; Coleoptera, Curculionidae, III part: Calandrininae I. Part, Sofia. In Bulgarian (1979).

19 Freude H, Harde KW and Lohse GA, Die käfer Mitteleuropas. Band 11. Krefeld: 340 p. In German (1983).

20 Morris MG, True weevils, part II (Coleoptera: Curculionidae, Ceutorhynchinae). Handbooks for the identification of British insects, vol. 5, part 17c. Royal entomological society, Bonehill (2008).

21 Meier U (ed.), Growth stages of mono-and dicotyledonous plants, BBCH Monograph. Sec. edn. Federal biological research centre for agriculture and forestry. Germany (2001).

22 Seidenglanz M, Poslušná $J$ and Hrudová E, The importance of monitoring the Ceutorhynchus pallidactylus female flight activity for the timing of insecticidal treatment. Plant Protect. Sci. 45, 3: 103-112 (2009).

23 McCullagh P, Regression models for ordinal data (with discussion). J. Roy. Statist. Soc. B 42 109-142 (1980).

24 Tutz G, Regression for categorical data. Cambridge University Press. p. 572 (2012).

25 Hilbe JM, Logistic Regression Models. Chapman \& Hall/CRC. P. 637 (2009).

This article is protected by copyright. All rights reserved. 
26 Kruskal JB and Wish M, Multidimensional Scaling. Number 07-011 in Sage University

Paper Series on Quantitative Applications in the Social Sciences. Sage Publications, Newbury Park (1978).

27 R Core Developmental Team, A language and environment for statistical computing. R Foundation for Statistical Computing, Vienna, Austria. (http://www.R-project.org/ 2015).

28 Ferguson AW, Nevard LM, Clark SJ and Cook SM, Temperature-activity relationships in Meligethes aeneus: implications for pest management. Pest Manag Sci, 71: 459-466 (2015).

29 Büchs W, Strategies to control the cabbage stem weevil (Ceutorhynchus pallidactylus Mrsh.) and the oilseed rape stem weevil (Ceutorhynchus napi Gyll.) by a reduced input of insecticides. IOBC Bulletin 21 (5): 205-220 (1998).

30 Moser D, Drapela T, Zaller JG and Frank T, Interacting effects of wind direction and resource distribution on insect pest densities. Basic Appl. Ecol. 10: 208-215 (2009).

31 Büchi R, Eiablage des Rapsstengelrüßlers Ceutorhynchus napi Gyll., in Abhängigkeit der Stengellänge bei verschiedenen Rapssorten. Anzeiger für Schädlingskunde, Pflanzenschutz, Umweltschutz. 69, 6: 136-139 (1996).

32 Zaller GJ, Moser D, Drapela T, Schmöger C and Frank T, Insect pests in winter oilseed rape affected by field and landscape characteristics. Basic Appl. Ecol. 9, 682-690 (2008a).

33 Inđić D, Vuković S, Grahovac M, Bursić V and Šunjka D, Problems in Ceutorhynchus spp. control on rapeseed in the region of Serbia. Pestic. Phytomed., 24, 4: 309-313 (2009).

This article is protected by copyright. All rights reserved. 
34 Zaller GJ, Moser D, Drapela T, Schmöger C and Frank T, Effect of within-field and landscape factors on insect damage in winter oilseed rape. Agric., Ecosyst. Environ. 123: $233-238(2008 b)$.

35 Milovac $\check{Z}$ and Kereši $T$, Possibility for decreasing damage made by weevils (Ceutorhynchus spp.) on oilseed rape. Book of abstracts of VI Congress on plant protection with Simposium on biological control of invasive organisms, Plant protection society of Serbia. Zlatibor, p 143 (2009).

36 Petraitiene E, Brazauskiene I and Vaitelyte B, The effect of insecticides on pest control and productivity of winter and spring oilseed rape (Brassica napus L.). In Insecticides - advances in integrated pest management (ed. by Farzana Perveen). InTech (2012). http://cdn.intechopen.com/pdfs-wm/25681.pdf

37 Vaitelyte B, Brazauskiene I and Petraitiene E, Species diversity of weevils (Ceutorhynchus spp.), migration activity and damage in winter and spring oilseed rape. Zemdirbyste-Agriculture, 100, 3: 293-302 (2013).

38 Grantina I and Turka I, The influence of synthetic insecticides on the dynamics of cabbage stem weevil (Ceutorhynchus pallidactylus Marsh.) and cabbage pod weevil (Ceutorhynchus obstrictus Marsh.) in winter oilseed rape. Proceedings of the Latvia University of Agriculture. 28, 1: 60-68. DOI: 10.2478/v10236-012-0016-Z (published online 02.06.2013).

39 McCullagh P and Nelder J, Generalized Linear Models, Second Edition. Chapman \& Hall/CRC. P. 532 (1989).

40 Eickermann M, Junk J, Hoffmann L and Beyer M, Forecasting the breaching of the control threshold for Ceutorhynchus pallidactylus in oilseed rape. Agricultural and Forest Entomology, 17: 71-78 (2015).

This article is protected by copyright. All rights reserved. 
41 Trnka M, Muška F, Semeradova D, Dubrovsk'y M, Kocmankova E. and Žalud Z, European Corn Borer life stage model: regional estimates of pest development and spatial distribution under present and future climate. Ecological Modelling, 207: 6184 (2007).

42 Bale J, Masters J, Hodkinson, D. et al., Herbivory in global climate change research: direct effects of rising temperature on insect herbivores. Global Change Biology, 8: $1-16(2002)$.

\section{Tables}

Table 1. Properties of the tested insecticides

\begin{tabular}{|c|c|c|c|c|c|c|}
\hline No. & Treatment & $\begin{array}{l}\text { Product } \\
\text { name }\end{array}$ & $\begin{array}{l}\text { Amount of } \\
\text { a.i. }(\mathrm{g} / \mathrm{L})\end{array}$ & $\begin{array}{l}\text { Application } \\
\text { rate }(\mathrm{L} / \mathrm{ha})\end{array}$ & Chemical group & $\begin{array}{c}\text { Group } \\
\text { according to } \\
\text { IRAC }^{\mathrm{a}}\end{array}$ \\
\hline 1. & $\begin{array}{c}\text { Control } \\
\text { (untreated) }\end{array}$ & - & - & - & - & - \\
\hline 2. & Bifenthrin & $\begin{array}{c}\text { Talstar 10- } \\
\text { EC }\end{array}$ & 100 & 0,2 & pyrethroid & $3 \mathrm{~A}$ \\
\hline 3. & $\begin{array}{c}\text { Alpha- } \\
\text { cypermethrin }\end{array}$ & $\begin{array}{c}\text { Fastac 10- } \\
\text { EC }\end{array}$ & 100 & 0,15 & pyrethroid & $3 \mathrm{~A}$ \\
\hline 4. & Pirimiphos-methyl & $\begin{array}{c}\text { Actellic- } \\
50\end{array}$ & 500 & 1 & organophosphates & $1 \mathrm{~B}$ \\
\hline 5. & Tau-fluvalinate & $\begin{array}{c}\text { Mavrik- } \\
\text { EW }\end{array}$ & 240 & 0,2 & pyrethroid & $3 \mathrm{~A}$ \\
\hline 6. & $\begin{array}{l}\text { Chlorpyriphos }+ \\
\text { cypermethrin }\end{array}$ & Nurelle-D & $500+50$ & 1 & $\begin{array}{c}\text { organophosphates }+ \\
\text { pyrethroid }\end{array}$ & - \\
\hline 7. & Thiacloprid & $\begin{array}{l}\text { Calypso } \\
480-\mathrm{SC}\end{array}$ & 480 & 0,15 & neonicotinoid & $4 \mathrm{~A}$ \\
\hline
\end{tabular}

${ }^{a}$ IRAC Insecticide Resistance Action Committee (http://www.irac-online.org/modes-of-action/)

This article is protected by copyright. All rights reserved. 
Table 2. Damage ratings scale based on tunnel length, damage severity and stem lodging probability

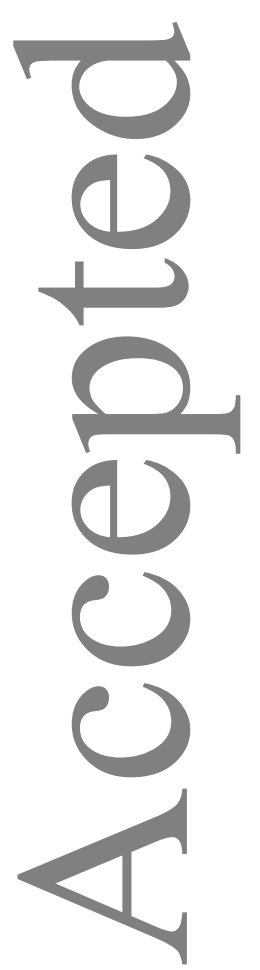

\begin{tabular}{|c|c|c|c|}
\hline Scale mark & Tunnel length (\%) & Damage severity & Stem lodging probability \\
\hline 0 & 0 & Without damage & none \\
1 & up to 10 & barely noticeable & none \\
2 & $11-25$ & visible & low \\
3 & $26-50$ & tunnels deep and long & medium \\
4 & $51-75$ & severe damage & high \\
5 & $76-100$ & most of stem has been damaged & almost certain \\
\hline
\end{tabular}

This article is protected by copyright. All rights reserved. 
Table 3. Total number of $C$. pallidactyllus and $C$. napi collected in yellow water traps

\begin{tabular}{|c|c|c|c|c|c|c|c|c|c|}
\hline \multirow{2}{*}{ Year } & \multirow{2}{*}{ Yellow trap } & \multicolumn{8}{|c|}{ Date } \\
\hline & & 09.03. & 16.03 . & 23.03 & 30.03 & 06.04 & 13.04 & 20.04 & 27.04. \\
\hline \multirow{4}{*}{2010} & 1. & $* *$ & $* *$ & 193 & 404 & 2 & 0 & 0 & 0 \\
\hline & 2. & $* *$ & $* *$ & 169 & 129 & 2 & 0 & 0 & 0 \\
\hline & 3. & $* *$ & $* *$ & 66 & 77 & 0 & 0 & 0 & 0 \\
\hline & 4. & $* *$ & $* *$ & 334 & 151 & 16 & 0 & 2 & 3 \\
\hline & & 10.03 & 17.03. & 23.03. & 01.04. & 06.04. & 14.04 & 21.04. & 29.04. \\
\hline \multirow{4}{*}{2011} & 1. & $* *$ & 1 & 4 & 3 & 3 & 0 & 0 & 0 \\
\hline & 2. & $* *$ & 0 & 1 & 4 & 0 & 1 & 1 & 0 \\
\hline & 3. & $* *$ & 1 & 3 & 1 & 1 & 0 & 0 & 0 \\
\hline & 4. & $* *$ & 0 & 1 & 13 & 0 & 0 & 0 & 0 \\
\hline & & 09.03. & 15.03 & 21.03. & 27.03 & 04.04. & 10.04 & 20.04 & 26.04 \\
\hline \multirow{4}{*}{2012} & 1. & $0 *$ & 0* & 0 & 0 & 1 & 7 & 1 & 0 \\
\hline & 2. & $0^{*}$ & 0* & 1 & $0^{*}$ & 0 & 2 & 2 & 0 \\
\hline & 3. & $0 *$ & 1 & 0 & 4 & 3 & 4 & 1 & 0 \\
\hline & 4. & $0 *$ & $0 *$ & 0 & 1 & 1 & 14 & 0 & 0 \\
\hline & & 06.03. & 12.03 & 20.03 & 28.03. & 04.04. & 12.04. & 18.04 . & 26.04 . \\
\hline \multirow{4}{*}{2013} & 1. & 2 & 69 & 2 & 4 & 0 & 8 & 0 & 0 \\
\hline & 2. & 2 & 14 & 3 & 2 & $0^{*}$ & 0 & 0 & 0 \\
\hline & 3. & 2 & 41 & 0 & 3 & $0 *$ & 1 & 0 & 0 \\
\hline & 4. & 1 & 19 & 1 & 4 & 3 & 3 & 0 & 0 \\
\hline
\end{tabular}

* Trap was damaged by frost or unfavourable weather conditions

** Assessments did not start due to temperatures below zero

This article is protected by copyright. All rights reserved. 
Table 4. Number of males and females of $\boldsymbol{C}$. pallidactyllus and C. napi collected in yellow water traps and their ratio

\begin{tabular}{|c|c|c|c|c|c|c|c|}
\hline Year/Species & C. pallic & llus & Sexual* & C. nal & & Sexual & C. palli./ $C$. \\
\hline & o & 오 & & $\hat{0}$ & 오 & & \\
\hline 2010 & 256 & 483 & 0.34 & 383 & 426 & 0.47 & 0.91 \\
\hline 2011 & 9 & 17 & 0.35 & 14 & 9 & 0.61 & 1.13 \\
\hline 2012 & 4 & 14 & 0.22 & 14 & 15 & 0.48 & 0.62 \\
\hline 2013 & 90 & 74 & 0.55 & 87 & 69 & 0.56 & 1.05 \\
\hline AVG.** & 359 & 588 & 0.37 & 498 & 519 & 0.49 & 0.93 \\
\hline
\end{tabular}

*Sexual index is represented as the ratio between the number of males and the total number of specimens

**Average for all years

This article is protected by copyright. All rights reserved. 
Table 5. Average number of larvae in stem (N) and insecticide efficacy (Ef.) for treatments from 2010 to 2013

\begin{tabular}{|l|r|r|r|r|r|r|r|r|}
\hline \multirow{2}{*}{ Treatment } & \multicolumn{2}{|c|}{ Year 2010 } & \multicolumn{2}{c|}{2011} & \multicolumn{2}{c|}{2012} & \multicolumn{2}{c|}{2013} \\
\cline { 2 - 10 } & N. & Ef. $^{\text {b }}$ & N. & Ef. & N. & Ef. & N. & Ef. \\
\hline Control (untreated) & 11.8 & - & 1.0 & - & 3.7 & - & 2.8 & - \\
Bifenthrin & 3.3 & 72.0 & 1.3 & - & 1.8 & 51.3 & 0.9 & 67.9 \\
Alpha-cypermethrin & 5.8 & 50.8 & 0.8 & 20.0 & 2.4 & 35.1 & 1.4 & 50.0 \\
Pirimiphos-methyl & 5.0 & 57.6 & 1.1 & - & 1.9 & 48.6 & 2.2 & 21.4 \\
Taufluvalinate & 11.5 & 2.5 & 1.4 & - & 2.6 & 29.7 & 2.3 & 17.9 \\
Chlorpyriphos + cypermethrin & 5.0 & 57.6 & 0.7 & 30.0 & 1.5 & 59.5 & 1.6 & 42.9 \\
Thiacloprid & 10.5 & 11.0 & 1.9 & - & 3.1 & 16.2 & 2.3 & 17.9 \\
\hline
\end{tabular}

${ }^{b}$ Efficacy (\%) was calculated based on Abbotts formula Ef.(\%) $=(1-\mathrm{Nt} / \mathrm{Nc}) \times 100$ where $\mathrm{Nt}$ refers to number of larvae in treated plot and Nc refers to number of larvae in control treatment.

This article is protected by copyright. All rights reserved. 
Table 6. Parameter estimates of the proportional odds model fitted to insect damage rating data

\begin{tabular}{|l|c|c|c|c|}
\hline \multirow{2}{*}{ Treatment } & \multicolumn{4}{|c|}{ Parameter estimates } \\
\cline { 2 - 5 } & 2010 & 2011 & 2012 & 2013 \\
\hline Cut-point $\theta_{0}$ & -4.476 & -0.962 & -3.845 & -3.799 \\
Cut-point $\theta_{1}$ & -3.185 & -0.129 & -3.206 & -1.996 \\
Cut-point $\theta_{2}$ & -1.971 & 0.864 & -2.679 & -0.492 \\
Cut-point $\theta_{3}$ & -0.598 & 2.368 & -2.049 & 0.952 \\
Cut-point $\theta_{4}$ & 1.065 & 3.932 & -1.175 & 2.612 \\
Bifenthrin & $-2.022^{* *}$ & -0.486 & $-2.040^{* *}$ & $-2.424^{* *}$ \\
Alpha-cypermethrin & $-1.760^{* *}$ & $-0.770^{* *}$ & $-0.985^{* *}$ & $-1.736^{* *}$ \\
Pirimiphos-methyl & $-1.418^{* *}$ & $-1.203^{* *}$ & $-1.766^{* *}$ & $-1.153^{* *}$ \\
Tau-fluvalinate & -0.317 & -0.407 & $-1.095^{* *}$ & $-0.778^{* *}$ \\
Chlorpyriphos + cypermethrin & $-1.670^{* *}$ & $-0.669 *$ & $-2.395^{* *}$ & $-2.924^{* *}$ \\
Thiacloprid & -0.387 & -0.028 & -0.629 & $-0.916^{* *}$ \\
\hline
\end{tabular}

* significantly different at the 0.05 level

** significantly different at the 0.01 level

This article is protected by copyright. All rights reserved. 
Table 7. Estimated probabilities of the proportional odds model fitted to insect damage rating data

\begin{tabular}{|c|c|c|c|c|c|c|c|}
\hline & Control & Bifenthrin & $\begin{array}{c}\text { Alpha- } \\
\text { cypermethrin }\end{array}$ & $\begin{array}{c}\text { Pirimiphos- } \\
\text { methyl }\end{array}$ & Taufluvalinate & $\begin{array}{c}\text { Chlorpyriphos }+ \\
\text { cypermethrin }\end{array}$ & Thiacloprid \\
\hline \multicolumn{8}{|c|}{2010} \\
\hline$\pi_{0}$ & 0.011 & 0.079 & 0.062 & 0.045 & 0.015 & 0.057 & 0.016 \\
\hline$\pi_{1}$ & 0.039 & 0.238 & 0.194 & 0.146 & 0.053 & 0.180 & 0.057 \\
\hline$\pi_{2}$ & 0.122 & 0.513 & 0.447 & 0.365 & 0.160 & 0.425 & 0.170 \\
\hline$\pi_{3}$ & $0.354^{*}$ & $0.806(1)$ & $0.761(2)$ & $0.694(4)$ & $0.430(6)$ & $0.745(3)$ & $0.447(5)$ \\
\hline$\pi_{4}$ & 0.743 & 0.956 & 0.943 & 0.923 & 0.799 & 0.939 & 0.810 \\
\hline \multicolumn{8}{|c|}{2011} \\
\hline$\pi_{0}$ & 0.277 & 0.383 & 0.452 & 0.560 & 0.365 & 0.427 & 0.282 \\
\hline$\pi_{1}$ & 0.468 & 0.588 & 0.655 & 0.745 & 0.569 & 0.632 & 0.475 \\
\hline$\pi_{2}$ & 0.704 & $0.794(4)$ & $0.837(2)$ & $0.887(1)$ & $0.781(5)$ & $0.823(3)$ & $0.709(6)$ \\
\hline$\pi_{3}$ & 0.915 & 0.945 & 0.959 & 0.972 & 0.941 & 0.955 & 0.916 \\
\hline$\pi_{4}$ & 0.981 & 0.988 & 0.992 & 0.994 & 0.987 & 0.990 & 0.981 \\
\hline \multicolumn{8}{|c|}{2012} \\
\hline$\pi_{0}$ & 0.021 & 0.141 & 0.054 & 0.111 & 0.060 & 0.190 & 0.039 \\
\hline$\pi_{1}$ & 0.039 & 0.237 & 0.098 & 0.191 & 0.108 & 0.308 & 0.071 \\
\hline$\pi_{2}$ & 0.064 & 0.345 & 0.155 & 0.286 & 0.170 & 0.430 & 0.114 \\
\hline$\pi_{3}$ & 0.114 & 0.497 & 0.256 & 0.429 & 0.278 & 0.586 & 0.195 \\
\hline$\pi_{4}$ & 0.236 & $0.703(2)$ & $0.452(5)$ & $0.643(3)$ & $0.480(4)$ & $0.772(1)$ & $0.367(6)$ \\
\hline \multicolumn{8}{|c|}{2013} \\
\hline$\pi_{0}$ & 0.022 & 0.202 & 0.113 & 0.066 & 0.046 & 0.294 & 0.053 \\
\hline$\pi_{1}$ & 0.120 & 0.606 & 0.436 & 0.301 & 0.228 & 0.716 & 0.254 \\
\hline$\pi_{2}$ & 0.380 & $0.874(2)$ & $0.777(3)$ & $0.660(4)$ & $0.571(6)$ & $0.918(1)$ & $0.605(5)$ \\
\hline$\pi_{3}$ & 0.722 & 0.967 & 0.937 & 0.892 & 0.849 & 0.978 & 0.867 \\
\hline$\pi_{4}$ & 0.932 & 0.994 & 0.988 & 0.978 & 0.967 & 0.994 & 0.971 \\
\hline
\end{tabular}

*Treatment ranks are added in parentheses and show insecticide efficacy

This article is protected by copyright. All rights reserved. 
Table 8. Cumulative probabilities of the proportional odds model fitted to insect damage rating data

\begin{tabular}{|c|c|c|c|c|c|c|c|}
\hline & Control & Bifenthrin & $\begin{array}{l}\text { Alpha- } \\
\text { cypermethrin }\end{array}$ & $\begin{array}{l}\text { Pirimiphos- } \\
\text { methyl }\end{array}$ & Taufluvalinate & $\begin{array}{c}\text { Chlorpyriphos + } \\
\text { cypermethrin }\end{array}$ & Thiacloprid \\
\hline \multicolumn{8}{|c|}{2010} \\
\hline$\gamma_{0}$ & 0.011 & 0.079 & 0.062 & 0.045 & 0.015 & 0.057 & 0.016 \\
\hline$\gamma_{1}$ & 0.028 & 0.159 & 0.132 & 0.101 & 0.038 & 0.123 & 0.041 \\
\hline$\gamma_{2}$ & 0.083 & 0.275 & 0.253 & 0.219 & 0.107 & 0.245 & 0.113 \\
\hline$\gamma_{3}$ & 0.232 & 0.293 & 0.314 & 0.329 & 0.270 & 0.320 & 0.277 \\
\hline$\gamma_{4}$ & 0.389 & 0.150 & 0.182 & 0.229 & 0.369 & 0.194 & 0.363 \\
\hline$\gamma_{5}$ & 0.257 & 0.044 & 0.056 & 0.077 & 0.201 & 0.061 & 0.190 \\
\hline \multicolumn{8}{|c|}{2011} \\
\hline$\gamma_{0}$ & 0.277 & 0.383 & 0.452 & 0.560 & 0.365 & 0.427 & 0.282 \\
\hline$\gamma_{1}$ & 0.191 & 0.205 & 0.203 & 0.185 & 0.204 & 0.205 & 0.193 \\
\hline$\gamma_{2}$ & 0.236 & 0.206 & 0.182 & 0.142 & 0.212 & 0.191 & 0.234 \\
\hline$\gamma_{3}$ & 0.211 & 0.151 & 0.122 & 0.085 & 0.160 & 0.132 & 0.207 \\
\hline$\gamma_{4}$ & 0.066 & 0.043 & 0.033 & 0.022 & 0.046 & 0.035 & 0.065 \\
\hline$\gamma_{5}$ & 0.019 & 0.012 & 0.008 & 0.006 & 0.013 & 0.010 & 0.019 \\
\hline \multicolumn{8}{|c|}{2012} \\
\hline$\gamma_{0}$ & 0.021 & 0.141 & 0.054 & 0.111 & 0.060 & 0.190 & 0.039 \\
\hline$\gamma_{1}$ & 0.018 & 0.096 & 0.044 & 0.080 & 0.048 & 0.118 & 0.032 \\
\hline$\gamma_{2}$ & 0.025 & 0.108 & 0.057 & 0.095 & 0.062 & 0.122 & 0.043 \\
\hline$\gamma_{3}$ & 0.050 & 0.152 & 0.101 & 0.143 & 0.108 & 0.156 & 0.081 \\
\hline$\gamma_{4}$ & 0.122 & 0.206 & 0.196 & 0.214 & 0.202 & 0.186 & 0.172 \\
\hline$\gamma_{5}$ & 0.764 & 0.297 & 0.548 & 0.357 & 0.520 & 0.228 & 0.633 \\
\hline \multicolumn{8}{|c|}{2013} \\
\hline$\gamma_{0}$ & 0.022 & 0.202 & 0.113 & 0.066 & 0.046 & 0.294 & 0.053 \\
\hline$\gamma_{1}$ & 0.098 & 0.404 & 0.323 & 0.235 & 0.182 & 0.422 & 0.201 \\
\hline$\gamma_{2}$ & 0.260 & 0.268 & 0.341 & 0.359 & 0.343 & 0.202 & 0.351 \\
\hline$\gamma_{3}$ & 0.342 & 0.093 & 0.160 & 0.232 & 0.278 & 0.060 & 0.262 \\
\hline$\gamma_{4}$ & 0.210 & 0.027 & 0.051 & 0.086 & 0.118 & 0.016 & 0.104 \\
\hline$\gamma_{5}$ & 0.068 & 0.006 & 0.012 & 0.022 & 0.033 & 0.006 & 0.029 \\
\hline
\end{tabular}

This article is protected by copyright. All rights reserved. 


\section{Figure caption}

Figure 1. Multidimensional scaling (MDS) plot presenting values for insecticides and years
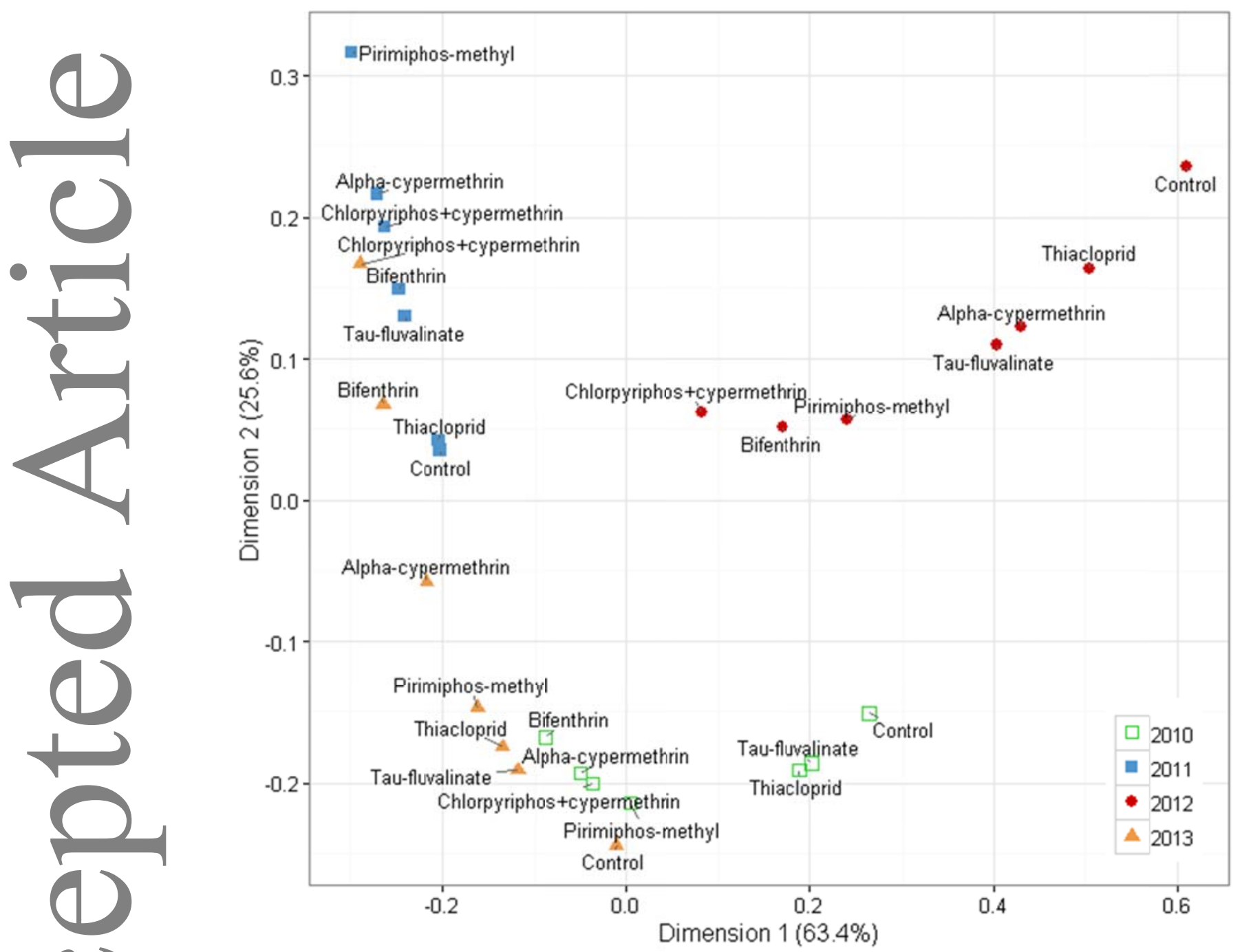

This article is protected by copyright. All rights reserved. 
Table 9. Sum of temperatures expressed in ${ }^{\circ} \mathrm{C}$ in the two critical periods (14 to 18 and 36 to 44 days from the beginning of the year)

\begin{tabular}{|c|c|c|c|c|c|c|c|}
\hline \multicolumn{2}{|c|}{ Year 2010} & \multicolumn{2}{|c|}{2011} & \multicolumn{2}{|c|}{2012} & \multicolumn{2}{|c|}{2013} \\
\hline 14-18 & $36-44$ & 14-18 & $36-44$ & 14-18 & $36-44$ & 14-18 & $36-44$ \\
\hline 0.2 & 2.0 & 8.7 & -0.6 & 0.5 & -10.9 & 4.5 & 4.8 \\
\hline 0.9 & -1.3 & 5.8 & 4.0 & -0.8 & -11.3 & 7.1 & 9.1 \\
\hline-1.5 & -0.8 & 4.9 & 3.0 & -1.2 & -9.0 & 4.2 & 1.1 \\
\hline 0.2 & -3.5 & 5.1 & 5.5 & -0.5 & -15.7 & 3.9 & 1.7 \\
\hline-0.5 & -4.2 & 1.2 & 3.5 & 0,6 & -18.3 & 0.4 & 0.1 \\
\hline & -1.2 & & 0.4 & & -17.2 & & -1.5 \\
\hline & 0.9 & & 4.5 & & -11.2 & & -1.8 \\
\hline & -0.6 & & 3.0 & & -8.9 & & 4.2 \\
\hline & -0.9 & & 0.8 & & -7.6 & & 4.5 \\
\hline-0.22 & -1.06 & 5.14 & 2.67 & -0.28 & -12.23 & 4.02 & 2.46 \\
\hline
\end{tabular}

This article is protected by copyright. All rights reserved. 